\title{
OS DESAFIOS PARA A INOVAÇÃO NA GESTÃO ESCOLAR EM MICRO E PEQUENAS EMPRESAS
}

\author{
LOS DESAFÍOS PARA LA INNOVACIÓN EN LA GESTIÓN ESCOLAR EN \\ PEQUEÑAS EMPRESAS
}

\author{
THE CHALLENGES FOR INNOVATION IN SCHOOL MANAGEMENT IN SMALL \\ COMPANIES
}

\author{
Maria Carolina Almeida DIAS ${ }^{1}$
}

RESUMO: A implementação de ações de inovação em micro e pequenas empresas (MPEs) é primordial para a ampliação da competitividade, aumento do faturamento e diversas modificações positivas nos diferentes setores da economia. No entanto, inovar traz questionamentos e incertezas, sobretudo nas MPEs. Sendo assim, o Programa Agentes Locais de Inovação (ALI), busca disseminar o conhecimento e orientar a prática de ações inovadoras nessas empresas. Sua metodologia envolve diagnósticos e acompanhamentos mensais, dentro de um período de 30 meses, divididos em 5 ciclos (0 à 4). Para este artigo, foram analisadas 8 empresas do segmento educacional, participantes do Programa ALI, pertencentes aos municípios de Marília e Assis, estado de São Paulo, com o objetivo de apresentar propostas de ações que visem melhorias no relacionamento com os alunos, enfatizando a clareza da proposta de valor da empresa e os diferenciais de cada uma. Para isso, foram realizadas pesquisas bibliográficas, estudo de campo para observação in loco e aplicação do diagnóstico Radar de Inovação, que mensura o grau de inovação global, em um conjunto de 13 dimensões. A partir disso, foi identificado que as empresas puderam colocar em prática diferentes ações de inovação em marketing, através do desenvolvimento das dimensões estudadas, apresentado melhora nos Ciclos 0 e 1 . As ações propostas também trouxeram resultados positivos no nível de satisfação dos alunos, além de um maior engajamento da comunidade com a escola.

PALAVRAS-CHAVE: Radar de inovação. Inovação em marketing. Escolas inovadoras.

RESUMEN: La implementación de acciones de innovación en pequeñas empresas es primordial para la ampliación de la competitividad, aumento del facturación y además modificaciones positivas en los diferentes sectores de la economia. Si embargo, innovar trae dudas y incertidumbres. Así, el Programa Agentes Locales de Innovación (ALI) búsqueda la diseminación del conocimiento y orientar la práctica de acciones innovadoras en las pequeñas empresas. Su metodología involucra cuestionarios y acompañamientos mensuales en un período de 30 meses, divididos em 5 ciclos $(0$ a 4). Para este artículo, foram estudiadas 8 empresas del segmento educativo, participantes del Programa ALI, de los municípios de Marília y Assis, estado de São Paulo, con el objetivo de presentar propuestas de acciones que mejorem la relación con los alumnos, enfatizando la claridad de la propuesta de valor y los diferenciales de las pequeñas empresas. Para eso, se realizaron investigaciones

${ }^{1}$ Universidade Federal de São Carlos (UFSCar), Sorocaba - SP - Brasil. Mestre em Sustentabilidade na Gestão Ambiental. ORCID: <https://orcid.org/0000-0002-8493-7620>. E-mail: carol.almeidadias@ gmail.com

RPGE- Revista on line de Política e Gestão Educacional, Araraquara, v.22, n.1, p. 424-438, jan./abr. $2018 \quad$ ISSN: 1519-9029 DOI: $10.22633 /$ rpge.v22.n.1.2018.10893 
bibliográficas, estudio de campo para observación in loco y aplicación del diagnóstico Radar de Innovación, que mide el grado de innovación global, en un conjunto de 13 dimensiones. A partir de eso, se identificó que las empresas pudieron poner en práctica diferentes acciones de innovación en marketing, a través del desarrollo de las dimensiones estudiadas, presentando mejora en los ciclos iniciales $\left(\begin{array}{lll}0 & \text { y } & 1\end{array}\right)$. Las aciones propuestas también trajeron resultados positivos en el nível de satisfacion de los alumnos, además de un maior compromisso de la comunidade con la escuela.

PALABRAS-CLAVE: Radar de innovación. Innovación en marketing. Escuelas innovadoras.

ABSTRACT: The implementation of innovation actions in small companies is essential for the expansion of competitiveness, increase of billing and many positive changes in the different sectors of the economy. However, innovate brings questions and uncertainties, especially in small companies. Therefore, the Program Local Innovation Agents (ALI Program) objective to disseminate knowledge and guide the practice of innovative actions in these companies. Its methodology involves diagnoses and monthly follow-ups, within a period of 30 months, divided into 4 cycles. For this article, were analysed 8 companies from the educational segment, participants of the ALI Program, belonging to the municipalities of Marilia and Assis, state of São Paulo, with the objective of proposing actions that aim at improving the relationship with students, emphasizing the clarity of the company's value proposition and the competitiveness of each. For this, was carried out bibliographical research, on-site study for observation and application of the Radar Innovation Diagnosis, which measures the degree of global innovation, in a set of 13 dimensions. From this, it was identified that the companies were able to put into practice different marketing innovation actions, through the development of the studied dimensions, presented improvement in Cycles 0 and 1. The proposed actions also brought positive results in the level of customer satisfaction, besides of greater engagement of students and community with the school.

KEYWORDS: Radar of Innovation. Innovation in marketing. Innovative schools.

\section{Introdução}

O segmento educacional possui particularidades no que diz respeito à relacionamento com clientes. Por se tratar de um serviço imaterial, como o conhecimento, o saber técnico e científico, a apresentação de sua proposta de valor percorre diferentes caminhos. A conquista de um novo aluno ou a permanência dos atuais deve considerar fatores como conhecer os ideais e objetivos de vida, identificar dificuldades de aprendizado para que não gerar barreiras de aprendizagem no processo educacional e apresentar os diferenciais obtidos a partir de uma qualificação. No que diz respeito ao ensino regular, pode ser até mais desafiador. Além do aluno, a escola deve conquistar seus responsáveis, mães, pais e demais familiares.

Tendo em vista esses desafios, o presente artigo busca responder a questões sobre quais ferramentas as escolas podem utilizar para se relacionar com os clientes, quais ações 
obtiveram sucesso e quais possibilidades poderiam ser melhor exploradas pelas micro e pequenas empresas (MPEs) do segmento educacional.

Fazem parte do recorte deste artigo, as MPEs do segmento educacional, situadas nos municípios de Assis e Marília, estado de São Paulo e que participam do Programa Agentes Locais de Inovação (ALI). O foco será a dimensão Relacionamento e Clientes do Radar de Inovação.

A importância de valorizar ações que visem a melhoria e a construção de novas formas de se relacionar com clientes e os diferenciais de uma escola, proporciona maior competitividade para as MPEs e maior satisfação de seus clientes.

Considerando-se essa preocupação, o objetivo geral deste artigo é propor ações que visem melhorias no relacionamento com os clientes, enfatizando a clareza da proposta de valor da escola e os diferenciais competitivos de cada empresa. Para isso, foi necessário analisar as dificuldades enfrentadas por elas no que diz respeito a esses fatores e identificar ações que desenvolveram a dimensão Relacionamento e Clientes e que obtiveram retorno tanto financeiro, quanto pedagógico e até mesmo social.

Para viabilizar essas análises e proposições, a pesquisa foi realizada através da revisão bibliográfica, coleta e análise de dados primários e secundários e análise do Radar de Inovação, tanto o grau de inovação global, quanto de cada dimensão estudada.

\section{Micro e Pequenas Empresas (MPEs) no contexto brasileiro}

As Micro e Pequenas Empresas (MPEs) possuem um papel fundamental na economia brasileira, contribuindo significativamente para a geração de empregos e para o PIB nacional. Segundo Sebrae (2015), 27\% do valor adicionado do PIB, em uma média dos anos de 2009 a 2011 é representado pelas MPEs, percentual que vem aumentando desde o início da série histórica, em 1985. A participação principal neste dado é referente ao setor de comércio e serviços, correspondendo a $18,7 \%$, sendo que a pequena indústria representa $8,3 \%$ do PIB nacional (SEBRAE, 2015). Numa escala regional, a influência das MPEs é ainda mais destacada. Segundo Santos (2008 apud DUARTE, 2013), são empresas que possuem maior flexibilidade e resposta às necessidades do mercado, por estarem mais próximas de seu público, conhecendo seus anseios e particularidades.

Com isso, a preocupação em manter o segmento das MPEs em crescimento é fundamental, principalmente na disseminação do conhecimento em inovação e tendências do setor em que atuam. A constante atenção em relação aos hábitos e necessidades dos seus 
clientes, bem como em novidades do mercado, suas oportunidades e ameaças são comportamentos de quem deseja inovar, manter-se competitivo e a frente de seus concorrentes.

Ressaltando sua importância socioeconômica, a porcentagem de pessoal ocupado por MPEs é significativa, representada por $25,2 \%$ no setor industrial, $42,9 \%$ no comércio e $32 \%$ em serviços, no triênio 2009 - 2011. O estado que mais contribui para este dado é São Paulo, com um percentual de $30,5 \%$ de pessoas inseridas no mercado de trabalho através das MPEs (SEBRAE, 2015).

Além da importância econômica, as MPEs geram empregos e beneficiam diversas famílias tanto em escala municipal, quanto regional. Há uma tendência na realização de ações regionais que beneficiam o todo - o pensar global e agir local - e as MPEs estão diretamente ligadas a isso. Os clientes estão em sua cidade, região e em alguns casos em todo o país, representado a força dessas empresas, que devem buscar suas oportunidades, sempre atentas às externalidades econômicas, ambientais, tecnológicas, entre outras (ORLANDI, s/d).

Tendo em vista os dados apresentados, as MPEs possuem fundamental relevância para a economia brasileira, havendo a necessidade de criar possibilidades para que estas empresas cresçam, se mantenham competitivas no mercado e possam ter acesso ao conhecimento e informação, buscando melhorias na gestão de sua empresa.

Neste aspecto, o Sebrae vem ao encontro destas necessidades, incentivando o empreendedorismo e oferecendo suporte para que as MPEs se capacitem, promovendo o conhecimento em diferentes áreas de uma empresa.

Tocante a isso, através do Programa ALI e entre outras ações, o Sebrae busca incentivar o acesso à inovação pelas pequenas empresas, aspecto que no Brasil ainda é pouco explorado, principalmente no investimento à Pesquisa \& Desenvolvimento (P\&D) (CALMANOVICI, 2011). A principal atividade inovadora das empresas no país, sobretudo da indústria, é relacionada à aquisição de máquinas e pouco relacionada à investimento em P\&D (IBGE, 2013).

\section{Inovação nas MPEs}

Os esforços realizados pelas empresas buscando mudanças e incrementos em suas atividades, visando aspectos de redução de custos e aumento do faturamento configuram diferentes tipos de inovação que, segundo o Manual de Oslo (OCDE, 2005) podem ser inovação em produtos e serviços, em processos, em marketing e inovação organizacional. 
As inovações trazem mudanças que se caracterizam por trazer resultados incertos, requererem investimentos, aproveitarem-se dos saberes advindos de inovações já implementadas, requererem a absorção de um novo conhecimento e proporciona o aumento da vantagem competitiva (OCDE, 2005).

Sendo assim, o Manual de Oslo (OCDE, 2005) vai indicar que as inovações podem ocorrer em um novo processo, lançamento de um novo produto ou serviço, ações de marketing e organizacionais. De maneira mais específica, uma inovação em processo se dá quando a empresa modifica significativamente seus métodos de produção e distribuição; uma inovação em produto está relacionada a um novo bem ou serviço, além de melhorias em produtos já existentes.

Por sua vez, inovação organizacional está ligada à novos métodos de organização interna da empresa, bem como novas formas de se relacionar com o ambiente externo. Já a inovação em marketing se dá quando a empresa realiza alterações no design de seus produtos e embalagens, busca atender as necessidades de seus clientes, insere novos métodos de estabelecimento de preços e de promoção dos bens ou serviços e ao tentar atingir um novo canal de venda (OCDE, 2005).

Diante disso, todos os segmentos têm possibilidade de inovar, tanto no setor industrial, quanto serviços e comércio, cabendo a cada empresa dentro de seu segmento estar atenta às oportunidades e realização de adequações que visem a implementação da inovação. No presente artigo, optou-se por abordar o tipo de inovação em marketing, por empresas do segmento educacional.

Segundo Sebrae (2009, p. 194), o que dá sentido à inovação são seus impactos e consequências produzidos na sociedade. Neste sentido, as inovações desenvolvidas pelas MPEs vão impactar direta ou indiretamente a população local, trazendo benefícios tanto aos seus clientes, quanto à sua equipe de colaboradores, os quais acabam compartilhando ideias e inserindo a inovação na prática cotidiana no meio empresarial.

Para Calmanovici (2011), a inovação é fundamental para implementar a competitividade entre as empresas e para isso, são necessários estímulos por intermédio de investimentos em ciência, bem como incubadoras e parques tecnológicos, institutos de ciência e tecnologia, entre outros que forneçam possibilidades para o desenvolvimento das inovações trazendo retorno para a sociedade (CALMANOVICI, 2011).

\section{Programa Agentes Locais De Inovação (ALI)}


Em consonância, visando a ampliação do conhecimento em inovação para diversos setores da sociedade, o Programa ALI surgiu da parceria do Sebrae com o Conselho Nacional de Desenvolvimento Científico e Tecnológico (CNPq), com o objetivo de levar o conhecimento acadêmico às MPEs, auxiliando-as a implementar ações de inovação em seus negócios, ampliando a competitividade, buscando o aumento do faturamento e redução de custos (SEBRAE, 2016).

O Programa ALI teve início em 2009 no estado do Paraná, com as características de atendimento in loco, gratuito, personalizado e continuado, considerando que a empresa deve participar de diversos ciclos dentro de um período de até 30 meses. Atualmente, o programa está presente em todos os estados brasileiros, fomentando a inovação em todos os setores econômicos (indústria, comércio e serviços) (SEBRAE, 2016).

O primeiro ciclo é composto pelas fases: sensibilização e adesão, aplicação dos diagnósticos de gestão e radar de inovação, devolutiva, matriz FOFA (Forças, Oportunidades, Fraquezas e Ameaças) e elaboração de plano de ação, com no mínimo 5 ações sendo elas de gestão e inovação. Após a fase de monitoramento, nos demais ciclos são repetidas as etapas: diagnósticos, devolutiva, matriz FOFA, plano de ação e acompanhamento.

Os atendimentos são realizados pelos agentes locais de inovação, que são bolsistas do CNPq capacitados pelo Sebrae. Cada ciclo tem a duração de aproximadamente 6 meses e para a empresa finalizá-lo é necessário a realização de pelo menos 3 ações, de acordo com as exigências da metodologia do programa.

\section{Radar de Inovação}

Como inovar é um ato contínuo dentro de uma empresa, sua mensuração ainda é complexa (OCDE, 2005). A referência internacional no que diz respeito aos conceitos e indicadores da inovação é apresentado no Manual de Oslo (OCDE, 2005), o qual apresenta indicadores pouco acessíveis às MPEs (SAWHNEY et al, 2006 apud SIMÕES et al, 2015).

Diante dessa dificuldade em mensurar o grau de inovação em MPEs, o diagnóstico Radar de Inovação foi desenvolvido a fim de aproximar os indicadores à realidade dessas empresas (SAWHNEY et al, 2006 apud SIMÕES et al, 2015). Ele é composto por 13 dimensões, sendo elas: Oferta, Plataforma, Marca, Clientes, Soluções, Relacionamento, Agregação de Valor, Processos, Organização, Cadeia de Fornecimento, Presença, Rede e Ambiência Inovadora. 
Para utilizar o mesmo questionário para todos os setores foi realizada uma adaptação para cada um deles (indústria, comércio e serviços) com as mesmas dimensões, porém com quantidade de itens diferenciada. Cada item é composto por 3 alternativas, as quais variam por inovação não inserida pela empresa (1 ponto), inovação incipiente ( 3 pontos) e inovação inserida de forma sistemática (5 pontos) (SIMÕES et al, 2015). De acordo com seu grau de inovação global, são consideradas 3 escalas: empresas pouco inovadoras, inovadoras ocasionais e inovadoras sistêmicas, dentro de uma pontuação que varia de 1 a 5 (BACHMANN; DESTEFANI, 2008).

Ao final, a soma de cada item em cada dimensão irá compor a pontuação global do Radar de Inovação, bem como considera-se também um horizonte temporal de 3 anos, visando mensurar de forma mais pontual as ações realizadas, reforçando a atitude proativa de empresas inovadoras (BACHMANN; DESTEFANI, 2008).

\section{Dimensão Relacionamento e Clientes}

Neste artigo, optou-se por abordar as dimensões Relacionamento e Clientes, devido a evolução que estas obtiveram nos radares do Ciclo 0 ao Ciclo 1 e pelas ações realizadas pelas empresas referentes a estas dimensões, as quais trouxeram resultados como o aumento de faturamento, mudança de comportamento do empresário e satisfação dos clientes.

Optou-se por trabalhar o segmento educacional e sua relação com as dimensões apontadas, uma vez que este segmento é composto por clientes alunos e clientes responsáveis financeiros (pais e outros que se responsabilizam pelo pagamento das mensalidades referentes aos cursos), sendo que a necessidade de inovar nestas dimensões é primordial para a competitividade do negócio.

A dimensão Relacionamento considera todo tipo de experiência do cliente, em qualquer momento dentro da empresa. É dividido em dois itens, o primeiro trata das facilidades que a empresa oferece, como sala de espera, cartões comemorativos, brindes, e, o segundo, refere-se as diferentes maneiras que a empresa se relaciona com seus clientes por meios eletrônicos e informatizados (MACEDO et al, 2014).

Tais aspectos têm como objetivo aproximar os clientes da empresa, visando maior envolvimento com os professores, diretores e demais colaboradores com seus clientes, bem como valorizar o sentimento de pertencimento do aluno à escola e a formação de uma rede colaborativa encontrada no ambiente escolar. 
A dimensão Clientes aborda as ações que a empresa realiza para aproximar-se de seus clientes, identificando necessidades não atendidas, bem como ampliar nichos de mercado e novos produtos para seus atuais e futuros clientes. A empresa atenta a essa dimensão, inova também em novos produtos e serviços, pois ao comunicar-se com seu público, identifica oportunidades não aproveitadas e amplia o nível de satisfação de seus clientes por meio da valorização de seus desejos para com a instituição.

Num ambiente escolar também é fundamental estar atento às necessidades direcionadas a questões pedagógicas, com um acompanhamento por um profissional especializado, bem como o interesse por novos cursos que possam complementar a proposta de oferta atual da empresa.

\section{Procedimentos Metodológicos}

Este artigo foi realizado a partir da coleta e análise de dados primários e secundários, revisão bibliográfica e entrevistas estruturadas com base no Radar de Inovação, abrangendo 8 (oito) empresas do segmento educacional, participantes do Programa ALI, localizadas nos municípios de Marília e Assis, estado de São Paulo.

Tais empresas enquadram-se como Microempresas (MEs) e Empresas de Pequeno Porte (EPPs) considerando-se a faixa de faturamento anual de até $\mathrm{R} \$ 360.000,00$ e de $\mathrm{R} \$$ 360.000,00 à $\mathrm{R} \$ 4.800 .000,00$, respectivamente (BRASIL, 2006).

As revisões bibliográficas e os dados secundários (IBGE) foram imprescindíveis para a análise dos dados do Radar de Inovação e comparações qualitativas de características das MPEs. Já os dados primários, sobretudo obtidos a partir do trabalho de campo, foram utilizados para identificação do problema de pesquisa.

Dentro do grupo das empresas estudadas, incluem-se instituições de ensino de nível básico e cursinho pré-vestibular (3 empresas); nível profissionalizante (3 empresas); pósgraduação (1 empresa) e escola de música (1 empresa).

Seguindo a metodologia de trabalho de campo do ALI, foram aplicados os diagnósticos Radar de Inovação e Diagnóstico Empresarial do Ciclo Inicial (Ciclo 0) e Ciclo 1 sendo que neste artigo, é evidenciada a evolução das dimensões Relacionamento e Clientes. Tais diagnósticos foram aplicados em conjunto com os proprietários das empresas e, em algumas vezes, com a presença de gerentes e coordenadores, objetivando a melhor qualidade e exatidão das informações. 
O Radar de Inovação pode ser considerado um roteiro de entrevista estruturado. Nesse sentido, o roteiro deve trazer vantagens para o pesquisador, no momento da quantificação e comparação de resultados (COLAGNESE; MELO, 1998, p.145).

Após os resultados dos diagnósticos, foi proposto um plano de ação, buscando melhorias nos aspectos de gestão e de inovação, sendo acompanhados mensalmente pelo agente, visando a aplicação das ações propostas e consequente melhoria nas dimensões.

De acordo com Fernandes (2011), dentro da pesquisa de campo deve-se apurar a atenção e a percepção do objeto de estudo, fazendo com que o entrevistado torne-se um interlocutor, transmitindo de fato seu ponto vista, proporcionando uma entrevista mais rica em detalhes e com pouca interferência do pesquisador.

Em cada aplicação dos diagnósticos e visitas de acompanhamento, foi fundamental a observação atenta do agente, tornando o levantamento dos dados mais próximo da realidade da empresa, além de buscar evidências que demonstrassem as práticas realizadas, para melhor orientação e indicação de melhorias.

\section{Apresentação, análise e discussão dos resultados}

O presente artigo apresenta os resultados do Radar de Inovação das empresas do segmento educacional participantes do Programa ALI nos municípios de Marília - SP e Assis - SP, as quais migraram do Ciclo 0 para o Ciclo 1 evidenciando sua evolução por meio da implementação de ações de inovação propostas no plano de ação elaborado pelo agente, em conjunto com as empresas e com colaboração da gestora local do programa.

Por questões de confidencialidade, foram ocultadas as identidades das empresas e posteriormente enumeradas, para que seus nomes fossem preservados. A média de colaboradores por empresa é próxima de 19 empregados. Apenas a Empresa 6 possui faixa de faturamento de Microempresa (ME) e as demais, Empresas de Pequeno Porte (EPPs). O tempo médio de funcionamento das empresas é de 10 anos e 6 delas estão localizadas no município de Marília-SP e 2 no município de Assis-SP, todas pertencentes ao Escritório Regional do Sebrae de Marília-SP.

A Tabela 1 apresenta as pontuações das empresas em cada dimensão e seus graus de inovação global no Ciclo 0 (R0) e Ciclo 1 (R1): 
Tabela 1: Pontuação das empresas por dimensão no Ciclo 0 (R0) e Ciclo 1 (R1)

\begin{tabular}{|c|c|c|c|c|c|c|c|c|c|c|c|c|c|c|c|c|c|}
\hline \multirow{2}{*}{\multicolumn{2}{|c|}{ Empresas }} & \multicolumn{2}{|c|}{ E1 } & \multicolumn{2}{|c|}{ E2 } & \multicolumn{2}{|c|}{ E3 } & \multicolumn{2}{|c|}{ E4 } & \multicolumn{2}{|c|}{ E5 } & \multicolumn{2}{|c|}{ E6 } & \multicolumn{2}{|c|}{ E7 } & \multicolumn{2}{|c|}{ E8 } \\
\hline & & R0 & R1 & R0 & R1 & R0 & R1 & R0 & R1 & R0 & R1 & R0 & R1 & R0 & R1 & R0 & R1 \\
\hline \multirow{13}{*}{ 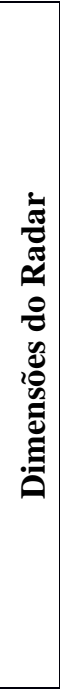 } & Oferta & 3,7 & 3,7 & 1,7 & 2,3 & 1 & 1 & 1,7 & 1,7 & 1,7 & 1,7 & 1 & 1,7 & 2,3 & 2,3 & 3,7 & 3,7 \\
\hline & Plataforma & 5 & 5 & 4 & 4 & 5 & 5 & 4 & 4 & 4 & 4 & 4 & 5 & 3 & 3 & 4 & 5 \\
\hline & Marca & 4 & 4 & 5 & 5 & 4 & 4 & 4 & 4 & 4 & 4 & 5 & 5 & 4 & 4 & 5 & 5 \\
\hline & Clientes & 3,7 & 4,3 & 2,3 & 4,3 & 1 & 3 & 1,7 & 1,7 & 2,3 & 2,3 & 2,3 & 3 & 2,3 & 3 & 1 & 2,3 \\
\hline & Soluções & 1 & 1 & 1 & 2 & 1 & 4 & 1 & 1 & 2 & 2 & 3 & 3 & 1 & 2 & 1 & 1 \\
\hline & Relacionamento & 5 & 5 & 4 & 4 & 4 & 4 & 1 & 4 & 1 & 4 & 3 & 5 & 2 & 5 & 4 & 5 \\
\hline & $\begin{array}{l}\text { Agregação de } \\
\text { valor }\end{array}$ & 2 & 2 & 1 & 1 & 2 & 3 & 2 & 2 & 2 & 2 & 2 & 4 & 2 & 2 & 1 & 4 \\
\hline & Processos & 3 & 3,3 & 2 & 2 & 1,3 & 2,7 & 2 & 1,7 & 1,7 & 2 & 1,7 & 2,7 & 2 & 1,7 & 2,7 & 3,3 \\
\hline & Organização & 3,7 & 4,3 & 2,3 & 3,7 & 1,7 & 2,3 & 1 & 1,7 & 2,3 & 3 & 1,7 & 3,7 & 1 & 1 & 1,7 & 2,3 \\
\hline & $\begin{array}{c}\text { Cadeia de } \\
\text { fornecimento }\end{array}$ & 3 & 3 & 3 & 3 & 1 & 1 & 3 & 3 & 1 & 1 & 1 & 1 & 1 & 1 & 3 & 3 \\
\hline & Presença & 1 & 3 & 2 & 2 & 1 & 1 & 2 & 2 & 1 & 1 & 1 & 1 & 1 & 1 & 2 & 2 \\
\hline & Rede & 3 & 5 & 3 & 3 & 1 & 5 & 1 & 1 & 1 & 1 & 3 & 3 & 3 & 3 & 3 & 3 \\
\hline & $\begin{array}{c}\text { Ambiência } \\
\text { inovadora }\end{array}$ & 2 & 2,7 & 1 & 1,3 & 1,7 & 2,7 & 1,3 & 1,7 & 1,3 & 1,7 & 1,3 & 2,7 & 2,3 & 2 & 2,3 & 3,7 \\
\hline \multicolumn{2}{|c|}{$\begin{array}{c}\text { Grau de Inovação } \\
\text { Global R0 e R1 }\end{array}$} & 3 & 3,5 & 2,4 & 2,8 & 2 & 3 & 1,9 & 2,2 & 1,9 & 2,2 & 2,2 & 3,1 & 2,1 & 2,4 & 2,6 & 3,4 \\
\hline
\end{tabular}

Fonte: Autoria própria. Dados coletados durante trabalho de campo, entre junho/2015 e abril/2017.

Com relação ao grau de inovação global obtido através do Radar de Inovação, as empresas alcançaram uma média de 2,3 no Ciclo 0 e evoluíram para uma média de 2,8 no Ciclo 1, uma diferença de 0,5 pontos. De acordo com a metodologia do Programa ALI, as ações realizadas a fim de migrar para um novo ciclo (Ciclo 1), poderiam estar direcionadas para melhorias na gestão da empresa e não somente ações de inovação, resultando assim em uma sensível melhora no grau de inovação global.

Ainda assim, pode-se observar que empresas tinham recebido destaque no grau de inovação global desde o Ciclo 0, como é o caso das empresas E1 e E8, que obtiveram pontuação maior que 2,5 , sendo classificadas respectivamente como inovadora ocasional e pouco inovadora (BACHMANN; DESTEFANI, 2008).

Referente ao Ciclo 1, destacam-se aquelas que obtiveram grau de inovação global mais elevado, sendo classificadas como inovadoras ocasionais as empresas E1, E3, E6 e E8 e, aquelas que obtiveram pontuação menos elevada, classificadas como pouco inovadoras, constituindo-se das empresas E2, E4, E5 e E7. Nota-se que metade se destacou com uma evolução mais significativa, com pontuação global maior que 3,0. Vale ressaltar também que a pontuação do Radar de Inovação vai de 1,0 a 5,0 pontos.

Tais resultados foram obtidos a partir da comparação dos dados da Tabela 1, analisando a média das pontuações por dimensão e a diferença de cada uma delas por ciclo 
(R0 e R1), resultando nas dimensões que mais evoluíram: Clientes, Relacionamento e Organização.

Nas dimensões Clientes e Relacionamento, foco deste artigo, a média das empresas no Ciclo 0 foi de 2,1 e 3,0 respectivamente. No Ciclo 1, as mesmas dimensões evoluíram para 3,0 em Clientes e 4,5 em Relacionamento. Obtendo uma evolução de 0,9 e 1,5 respectivamente. Estes dados refletem o empenho das empresas, que buscaram ampliar ações com foco na melhoria do relacionamento com seus clientes, como por exemplo, ações que buscam identificar necessidades através de pesquisas de satisfação, facilidades oferecidas, ampliação da atuação em redes sociais, entre outras.

\section{Impacto das principais ações implementadas}

Com base nas informações do Radar de Inovação, foi possível identificar quais oportunidades de melhorias poderiam ser realizadas, de forma a desenvolver as dimensões e consequentemente implementar inovações dentro das empresas. No âmbito das dimensões Clientes e Relacionamento foram propostas 7 categorias de ações no ciclo 0 , conforme é apresentado na Tabela 2:

Tabela 2: Ações previstas no plano de ação do Ciclo 0

\begin{tabular}{|c|c|c|c|c|c|c|c|c|c|c|c|}
\hline \multicolumn{3}{|r|}{ Empresas } & E1 & E2 & $\mathbf{E 3}$ & E4 & E5 & E6 & E7 & E8 & $\begin{array}{l}\text { Total de } \\
\text { ações }\end{array}$ \\
\hline \multirow{6}{*}{ 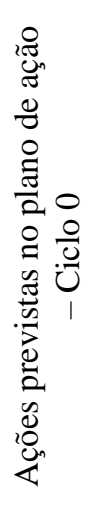 } & 1 & $\begin{array}{c}\text { Divulgação de depoimentos de alunos e } \\
\text { ex-alunos }\end{array}$ & 1 & - & - & - & - & 1 & - & - & 2 \\
\hline & 2 & $\begin{array}{c}\text { Área aluno e pré-matrícula no site da } \\
\text { empresa }\end{array}$ & 1 & - & - & - & - & - & - & $\mathrm{X}$ & 1 \\
\hline & 3 & $\begin{array}{c}\text { Ampliar redes sociais (Canal } \\
\text { Youtube/Fanpage) }\end{array}$ & 1 & 1 & 1 & 1 & 1 & - & 1 & 1 & 7 \\
\hline & 5 & Facilidades oferecidas & $\mathrm{X}$ & 2 & $X$ & - & 1 & - & $X$ & 1 & 4 \\
\hline & 6 & Projetos e eventos pedagógicos & - & 1 & 1 & 1 & 2 & - & - & 1 & 6 \\
\hline & 7 & $\begin{array}{c}\text { Pesquisa de satisfação e Identificação de } \\
\text { necessidades dos clientes }\end{array}$ & - & 1 & 1 & 1 & $X$ & 1 & 1 & 1 & 6 \\
\hline
\end{tabular}

Fonte: Autoria própria. Dados coletados durante trabalho de campo, entre junho/2015 e abril/2017.

Para a elaboração da Tabela 2, foram inseridas as categorias de ações contidas nos planos das empresas no Ciclo 0, de acordo com sua realização ou com o interesse das empresas em realizá-las. Sendo assim, consta assinalado com um X aquelas ações que não foram finalizadas em tempo para início do Ciclo 1 e inserido o número de ações quando consideradas finalizadas. Por exemplo, a Empresa E8 se propôs a inserir a ação 2 (pré- 
matrícula no site), porém não a realizou ao fim do Ciclo 0, já a Empresa E1 finalizou a ação. Para as demais empresas não foram propostas estas ações (Ciclo 0).

A Empresa E1 realizou a ação referente a busca de depoimentos de ex-alunos, da mesma forma que a Empresa E6. Esta ação poderia ser realizada a partir do levantamento, registro e divulgação tanto no site, quanto nas redes sociais da empresa de depoimentos de alunos e ex-alunos.

Visando maior rapidez e agilidade no atendimento, foi proposta a categoria de ação que orienta a implantação de uma área de aluno no site da empresa, inserindo dados acadêmicos, financeiros e diversas informações que se referem ao dia a dia da escola. Tal ação facilita o acesso tanto dos responsáveis, quanto dos próprios alunos, ao consultar faltas e notas, informações e recados, entre outras funcionalidades.

Também visando atingir mais pontos de venda, foi sugerido a implantação de prématrícula no site, facilitando o processo de fechamento de matrículas e trazendo maior garantias de formação de turmas para as escolas. A Empresa E1 teve possibilidade de finalizar a ação, já a Empresa E8 está em processo de finalização deste recurso.

Como tendência, as redes sociais têm se tornado uma oportunidade de divulgação para as empresas. Sendo assim, foi sugerida a ampliação das redes sociais, como a criação ou maior frequência de postagens na rede social Facebook, inserção de novas redes como YouTube, Instagram, entre outros visando maior presença na internet e desenvolvimento do marketing digital. Todas as empresas que inseriram esta ação no plano, conseguiram desenvolvê-la.

Na categoria de Facilidades oferecidas aos clientes, poderiam ser implantadas áreas de convivência dentro das escolas, com internet livre, café e até mesmo cantinas para os alunos que aguardam o início das aulas, bem como o estabelecimento de parceria com empresas, através de cartão convênio para os alunos, oferecendo descontos e vantagens para quem está matriculado na escola. As empresas E1, E3 e E7 não finalizaram a ação, sendo realizada pelas empresas E2, E5 e E8.

A ação que envolve Projetos e Eventos Pedagógicos foi desenvolvida de diversas formas. Elaborando feiras de profissões, feiras de ciências, peças de teatro e música, entre outras manifestações artísticas e pedagógicas. Tal ação, conforme relato das empresas, trouxe reflexos positivos no ambiente escolar e com a comunidade no geral, inclusive familiares. Benefícios relacionados com o nível de satisfação com a escola, professores, bem como no desenvolvimento pessoal e profissional também foram identificados pelas empresas que realizaram esta ação, sendo elas as empresas E2, E3, E4, E5 e E8. 
As ações relacionadas entre 1 e 6 desenvolveram principalmente a dimensão Relacionamento, considerando que a ação de número 7 (Pesquisa de Satisfação e Identificação de necessidades dos clientes), reflete impacto direto na dimensão Clientes, pois ao buscar identificar necessidades não atendidas, bem como novos cursos e serviços de interesse de seus alunos, a escola pode melhorar tanto sua oferta, quanto seus processos em geral. As empresas que realizaram a ação foram a E2, E3, E4, E6, E7 e E8. Porém, a empresa E5 não finalizou a ação, mesmo assim foi migrada para o plano do Ciclo 1.

Pode-se concluir, diante das categorias de ações citadas na Tabela 2 que o tipo de inovação de acordo com o Manual de Oslo, é classificada como inovação em marketing. Ao buscar atender as requisições de seus clientes (ação 7), ao tentar atingir um novo posicionamento da empresa em novo canal de venda (ação 2) e novas formas de promover seus serviços (ação 6), as empresas estão praticando inovações em marketing (OCDE, 2005).

\section{Considerações finais}

Diante do exposto neste artigo, as ações propostas para as empresas desenvolverem o relacionamento com seus clientes trouxeram impactos positivos tanto na evolução nas dimensões estudadas (R0 e R1), quanto em melhorias provenientes das inovações em marketing.

Durante o trabalho de campo, sobretudo na fase de diagnósticos, observou-se diversas barreiras enfrentadas pelas empresas para o desenvolvimento das ações, como falta de preparo, maneiras de aplicar as ações, entre outras. Neste momento o Programa ALI e o Escritório Regional do Sebrae Marília-SP foram fundamentais no auxílio e orientação prática das ações, de acordo com os objetivos de criação do ALI.

No que diz respeito a metodologia deste artigo, o foco dado à evolução do Radar de Inovação nos ciclos 0 e 1 trouxe vantagens tanto na comparação do grau de inovação global, quanto na pontuação em cada uma das 13 dimensões, possibilitando uma análise quantitativa das inovações implementadas. Já a atenção dada ao impacto das ações propostas e realizadas pelas empresas foi fundamental, podendo assim discorrer de forma qualitativa, complementando o estudo deste artigo.

Por fim, as ações direcionadas para uma melhor experiência do cliente e relacionamento com o mesmo puderam trazer inovações às escolas analisadas, favorecendo um maior nível de satisfação dos clientes, seu engajamento com a escola e comunidade e consequentemente aumento do nível de competividade das empresas. 
AGRADECIMENTOS: Ao CNPq e Sebrae Nacional, pelo financiamento da pesquisa através do Programa ALI.

\section{REFERÊNCIAS}

BACHMANN, D. L.; DESTEFANI, J. H. Metodologia para estimar o grau das inovações nas MPE. Curitiba, 2008. Disponível em:

<www.bachmann.com.br/website/documents/ArtigoGraudeInovacaonasMPE.pdf>. Acesso em: 07 fev. 2017.

BRASIL. Lei Complementar 123, de 14 de dezembro de 2006. Institui o Estatuto Nacional da Microempresa e da Empresa de Pequeno Porte. Disponível em:

<http://www.planalto.gov.br/ccivil_03/leis/LCP/Lcp123.htm>. Acesso em: 01 maio 2017.

CALMANOVICI, A. Inovação, a competitividade e a projeção mundial das empresas brasileiras. Revista USP, São Paulo, n.89, p.190-203, mar./maio, 2011

COLAGNESE, S. A.; MÉLO, J. L. B. A Técnica de entrevista na pesquisa social. Cadernos de Sociologia, Porto Alegre, v. 9 p. 143- 1559. 1998.

DUARTE, E. M. O empreendedorismo nas micro e pequenas empresas: um estudo aplicado à cidade de Pará de Minas - MG. 2013. 88 fls.Dissertação de Mestrado). Faculdades Pedro Leopoldo - Pedro Leopoldo, MG, 2013.

FERNANDES, M. E. Vivências de campo: o ofício do pesquisador. São Paulo: Cultura Acadêmica, 2011. 172 p.

IBGE. Pintec: pesquisa de inovação tecnológica. 2011. IBGE - Coordenação de indústria, Rio de Janeiro, 2013.

MACEDO, A. M.; POREM, M. E.; ANDRELO, R. Comunicação organizacional e inovação em micro e pequena empresa: um estudo sobre a aplicação do "Radar da Inovação"

Comunicação e Sociedade, v. 26, 2014, p.109-135. Centro de Estudos de Comunicação e Sociedade (CECS) Universidade do Minho, campus de Gualtar Braga, Portugal.

OCDE. Manual Oslo: Diretrizes para coleta e interpretação de dados sobre inovação. OCDE publishing. 3 ed. Paris, 2005.

ORLANDI, P. Las Pymes y su rol en el Comercio Internacional. Universidade de Palermo. Series del Centro de Estudios para el Desarrollo Exportador - CEDEX. Buenos Aires, jun./2006 Disponível em:

<http://www.palermo.edu/cedex/pdf/pyme_com_internacionall.pdf $>$. Acesso em: 08 fev. 2017.

SEBRAE, Serviço Brasileiro de Apoio às Micro e Pequenas Empresas. Cartilha Faça Diferente. Inovar é um Ótimo Negócio. Brasília, 2009.

SEBRAE, Serviço Brasileiro de Apoio às Micro e Pequenas Empresas. Participação das Micro e Pequenas Empresas na Economia Brasileira. Relatório Executivo. Brasília, 2015. 
Disponível em:

<http://www.bibliotecas.sebrae.com.br/chronus/ARQUIVOS_CHRONUS/bds/bds.nsf/e55cdb 1932bc40120b21bf4d277bb6ea/\$File/5307.pdf>. Acesso em: 08 fev. 2017.

SEBRAE, Serviço Brasileiro de Apoio às Micro e Pequenas Empresas. Programa ALI. Disponível em: <www.sebrae.com.br>. Acesso em: 04 dez. 2016.

SIMOES, L.C.; OLIVEIRA, M. A. C.; MENDES, D. R. F.; PINHEIRO, A. A. Radar da inovação: um estudo de caso das prestadoras de serviço de Brasília/DF. Revista de

Empreendedorismo e Gestão de Pequenas Empresas, Curitiba v. 4, n.2, 2015.

\section{Como referenciar este artigo}

DIAS, Maria Carolina Almeida. Os desafios para a inovação na gestão escolar em micro e pequenas empresas. Revista on line de Política e Gestão Educacional, Araraquara, v. 22, n. 1, p. 424-438, jan./abr., 2018. ISSN: 1519-9029. DOI: 10.22633/rpge.v22.n.1.2018.10893

Submetido em: 16/01/2018

Aprovado em: 25/03/2018 